\title{
Biskoppen og asketen
}

\section{Post-aksial kompromisreligion og Aarhus Domkirkes altertavle ${ }^{1}$}

\author{
HANS J. LUNDAGER JENSEN
}

ENGELSK SUMMARY: The sculptures on the altarpiece of Aarhus Cathedral are a good example of 'analogism', an understanding of reality (an 'ontology') that presents an ideal reality as a harmonious order. The altarpiece sought to mediate between two in principle different types of religions: archaic religion, typical of the great cultures of ancient times, claiming a divinely guaranteed good and beautiful hierarchical world, and the axial rejection of the known reality as evil, false and full of suffering. This attempt of mediation is what defines Christianity and other great religions after the axial rebellion: The world is fundamentally bad and in need of redemption and salvationand yet basically good and beautiful, with room for small, local miracles. These religions can therefore be regarded as 'post-axial compromise religions'.

DANSK RESUME: Skulpturerne på altertavlen i Aarhus domkirke er et godt eksempel på 'analogisme', en virkelighedsforståelse (en 'ontologi') der fremstiller en ideel virkelighed som en harmonisk orden. Altertavlen søgte at mediere imellem to i princippet forskellige religionstyper: den arkaiske, typisk for den nærorientalske oldtids store kulturer, der hævdede en guddommeligt garanteret god og smuk hierarkisk verden, og den aksiale, der forkastede den kendte virkelighed som mangel- og lidelsesfuld. Dette medieringsforsøg er hvad der definerer de store religioner efter de aksiale oprør. Verden er grundlæggende ond og længes efter forløsning og frelse - men samtidig smuk og god, med plads til små, lokale mirakler. Disse religioner kan derfor betragtes som 'postaksiale kompromisreligioner'.

KEYWORDS: altar piece; Aarhus cathedral; archaic religion; analogism; Philippe Descola; Robert Bellah; Emile Durkheim; Vasco da Gama

1 Artiklen her bygger på en kort forelæsning ved et seminar på Aarhus Universitet, fredag d. 23. febr. i anledning af Armin W. Geertz' 70-årsdag under titlen: “Post-aksial kompromisreligion', velsignelse og/eller askese: En kommentar til altertavlen i Aarhus Domkirke på baggrund af teorier om religionshistorisk evolution (Robert Bellah) og ontologiske skemaer (Philippe Descola)". 
Ved afdelingen for Religionsvidenskab ved Aarhus Universitet har vi i nogle år efterhånden diskuteret religionshistoriske teoridannelser, begrebsligheder og komparation på nye præmisser - $\mathrm{i}$ håbet om at 'religionshistorien' i mere præcis forstand som 'historie', dvs. registrering af og evt. forklaring på tidsligt bestemte forandringer og aflejringer, kunne styrke religionsvidenskabens diakrone dimension. Synkrone beskrivelser af religiøse systemer, tilstande, myter, ritualer og sociale praksisser er en uundværlig del; men disse er uundgåeligt taget ud af altid bevægelige forandringsprocesser, ikke kun lokalt og regionalt, men også som dele af kulturevolutionære megatrends.

Når det følgende har en altertavle som sin genstand, dvs. et empirisk-historisk eksempel, er det også for at gøre mig selv og andre opmærksomme på at religionsvidenskaben stadigvæk mangler metodiske og pædagogiske greb til at håndtere andre kildetyper end tekster. Dette er ikke mindst føleligt når det drejer sig om 'arkaisk religion' (jf. nedenfor), dvs. den type religion der dannedes samtidig med oldtidens tidligste statslige organisationer, og som netop artikulerede sig først og fremmest igennem ikoniske og indeksikale tegn, ${ }^{2}$ altså igennem ting, billeder, bygninger, skulpturer og processioner. En kristen altertavle kan selvfølgelig ikke umiddelbart henføres til arkaisk religion. Men kristendommen og andre 'historiske religioner' der fulgte efter 'aksetidens' oprør imod arkaisk religion (eksemplarisk i den tidlige buddhismes opgør med brahminsk præste- og offerreligion), fortsatte og gendannede, paradoksalt nok, på mange måder arkaisk religion.

Jeg vil her forstå middelalderkristendom som en 'post-aksial kompromisreligion', dvs. en religion der medierer imellem arkaisk religion og aksial religion (eller antireligion), imellem en religionsform hvis formål er at opretholde en tålelig, realistisk verdensorden, og en religionsform der er funderet i den dobbelte overbevisning om den realistiske verdens elendighed og et transcendent alternativs lyksaligheder. Arkaisk religion vil stabilisere verden; aksial religion vil bryde med den. Kompromisreligionen vil stabilisere verden og gøre den så beboelig som mulig, indtil dens beboere forlader den og, forhåbentlig, flyttes til den anden og bedre verden.

Mine overvejelser i det følgende vil handle om og slynge sig omkring altertavlen i koret i Aarhus Domkirke. ${ }^{3}$ Den kan dateres præcist. If. en indskrift på tavlen blev den opstillet i 1479. Den blev fremstillet på mester Bernt Notkes værksted i Lübeck og bestilt og betalt af den magtfulde Aarhusbiskop Jens, i eftertiden kendt som 'Jens

2 Jf. Roy Rappaport (1999) og hans gengivelse af en grundsondring imellem tegntyper if. Charles Sanders Pierce, jf. min korte introduktion (Lundager Jensen, 2003): Ikoniske tegn er tegn der i en eller anden forstand ligner hvad de betegner (fx statuer); indeksikale tegn er tegn der står i en umiddelbar kontakt med det de betegner, fx ved at være virkninger, hvorfra man kan slutte sig til årsagen (fx den sorte sten i Kabaen i Mekka).

3 Jeg har konsulteret vigtige forskningsbidrag: Moltke 1970; Kaspersen 1999; Plathe \& Bruun 2010, 1275-1287. 
Iversen Lange' ${ }^{4}$ Oven i prisen på 800 mark lagde biskoppen 20 rhinske gylden i drikkepenge og en hest. Selve tavlen, if. dens latinske indskrift, blev opstillet til Guds pris og Sankt Clemens ære og, også, til erindring om biskop Jens. ${ }^{5}$

En kort tekst som denne kan ikke komme i nærheden af en grundig religionshistorisk analyse af denne altertavle. ${ }^{6}$ Jeg begrænser mig til at kommentere nogle få, udvalgte dimensioner. Jeg vil kun se på tavlens hovedfelt, dvs. ikke på topskabet og figurerne omkring den eller på billederne på fodstykket, og kun på den inderste række og altså ikke på de malede billeder på de to lag låger (såkaldte 'anden' og 'tredje stand'), som tavlen er udstyret med. Jeg vil anlægge en slags strukturel tilgang, dvs. at jeg vil fokusere på relationer imellem elementerne, altså skulpturerne, i tavlen. En sådan strukturel tilgang vil være oplagt hvis det drejer sig om at rekonstruere de tankegange som tavlen har skullet illustrere eller belære om, altså biskop Jens' formodede intentioner med tavlens indhold og betydning - eller evt. de tankegange der traditionelt har begrundet en tavle af denne type (i fald biskop Jens mindre selvstændigt har overtaget et allerede fastlagt koncept).

Denne dimension kan man kalde den 'teologiske', og uden den ville man ingen ide kunne have om hvad tavlen 'selv vil sige'. Men en sådan tilgang har også en tendens til at etablere en færdig, solid konstruktion, en art 'lærebygning', en verdensopfattelse eller et værdisystem (eller et udsnit heraf) af en 'absolut' karakter. Jeg går ud fra at hensigten med tavlen faktisk er at give indtryk af en sådan fast konstruktion, altså i en eller anden forstand at belære og insistere. Men her vil jeg se på noget andet, nemlig at man også kan iagttage eller fornemme dobbeltheder, skævheder, asymmetrier og ustabiliteter i den tilsyneladende så faste konstruktion. Og det er formentlig i sådanne ridser og åbninger i den solide konstruktion, at forandringer i tid kan mærkes. Hvis rekonstruktion af en given tankegang kan kaldes 'teologi' eller, i religionshistorisk kontekst, for 'religionsantropologi' (hvis man med 'teologi' forstår produktet af menneskelige teologers aktiviteter), vil religionshistorien (i prægnant forstand, som noget andet end religionsantropologi) fokusere på processer, dvs. på strukturers opkomst, undergang, styrkelse, svækkelse, transformationer og evolution.

\footnotetext{
Tak til prof. Per Ingesman for denne præcision.

Indskriften lyser i sin fulde ordlyd: A(n)no d(omi)ni m cccclxxix Reuere(n)d(us) i(n) $x$ (=Christo) $p(a) t(e r)$ (et) d(omi)n(us) d(omi)n(us) Ihe(n)s Ep(iscop)us arhusien(sis) Ista(m) tabula(m) de(di)t ad laud(em) dei et ad ho(no)re(m) sa(ncti) cleme(n)t(is), dvs. ca. 'I det Herrens år 1479 gav den ærværdige fader og herre i Kristus, hr. Jens biskop i Aarhus, denne tavle til Guds pris og til ære for Sankt Clemens' (det vigtigste ord synes at være 'dominus', 'herre', 'hr.').

6 Indsigter fra kirkehistorien og kunsthistorien (jf. henvisningerne i note 3) er uundværlige; i denne sammenhæng ville de så være deldiscipliner af en mere omfattende religionshistorie.
} 


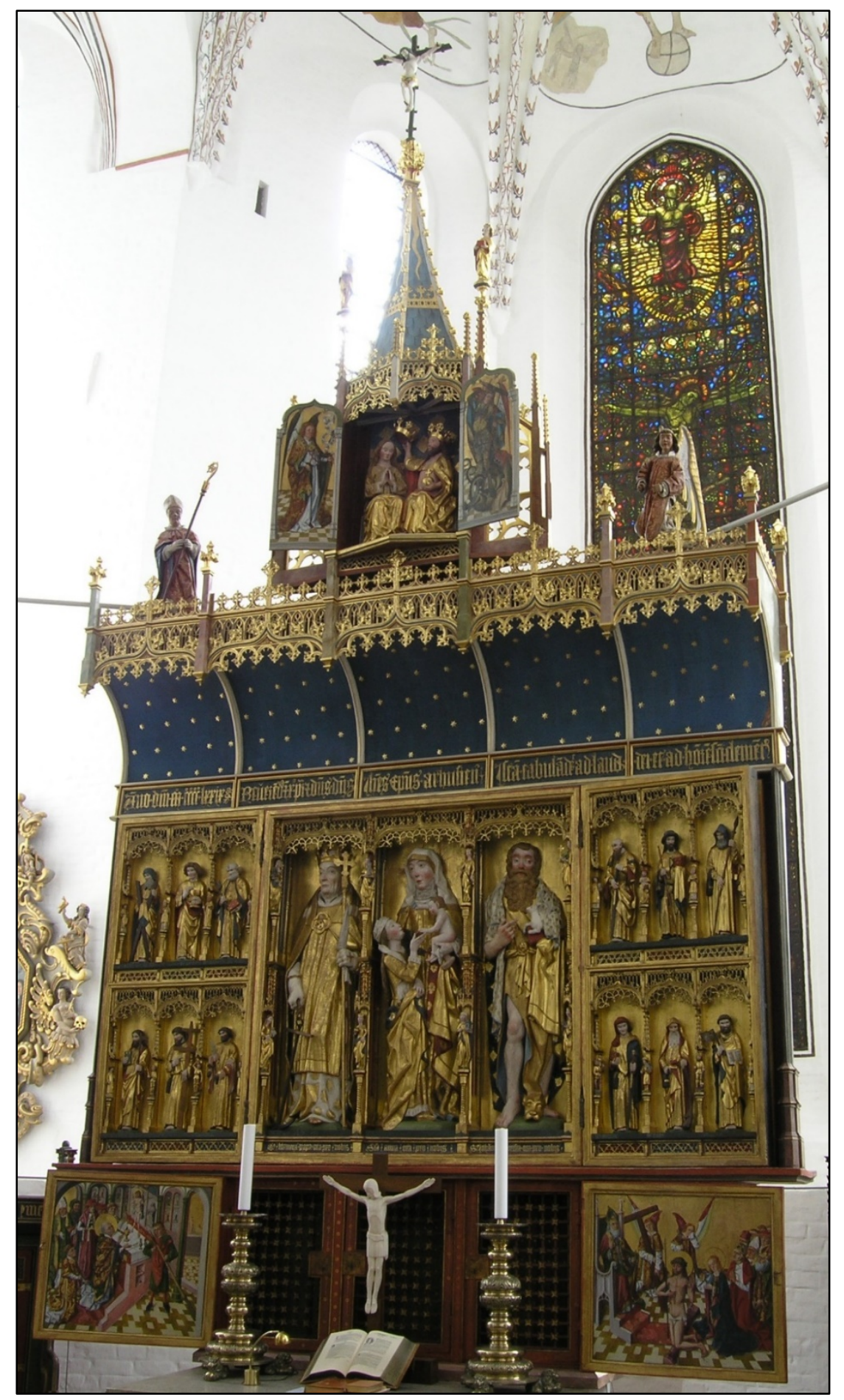

Foto: Jens Bruun @); jf. Plathe \& Bruun 2010, 1281. Billedet viser den såkaldte 'festside', dvs. den inderste række af afbildninger, der består af skulpturer. Nederst er lågerne for fodstykket, predellaen, åbnet. To ydre sæt af låger har malede billeder af hhv. Sankt Clemens og Johannes Døberen (1. stand) og af Jesu lidelseshistorie (2. stand). 


\section{Over-mennesker}

Et bud på hvad der først kan falde i øjnene, er tavlens mangfoldighed af skikkelser. Der er i alt 39. Hver af personerne, hellige skikkelser, repræsenterer en fortælling, kort eller længere, om deres martyrium eller deres efterlignelsesværdige liv; hver af skulpturerne er en indledningen til en fortælling, et vita, som kunne overleveres og gengives mundtligt eller skriftligt, som selvstændig tekst eller som kapitel i en samling af levnedsskildringer som, for at nævne det mest kendte eksempel, Iacobus de Voragines Legenda aurea fra anden halvdel af 1200-tallet. Alle disse personer har været mennesker, og alle er de, som den tyske filosof Peter Sloterdijk med rette siger, overmennesker, super-mennesker. ${ }^{1}$ Det er nærliggende at forstå helgenmylderet som en slags polyteisme, selvom dette går imod den officielle teologis protester og subtiliteter. Og der er bestemt også noget i den retning i helgendyrkelsen, som jeg vil komme tilbage til.

Men der er også noget andet, eller rettere: det stik omvendte. Helgener er ikke guder, der er kommet til jorden, men en slags anti-guder: mennesker, der er steget til himmels. Alle er de gået til ekstremer som de fleste ikke ville kunne magte og som de fleste gerne vil skånes for. Men mens mennesker i egentlig polyteisme ikke kan blive til guder og guder ikke til mennesker (eller kun igennem en langvarig proces i mange led, som i indisk karma-tænkning), kan mennesker i middelalderkristendom faktisk blive til guddommelige væsener (og flertallet vil også blive det, til sidst).

Tavlen her er et så godt eksempel som muligt på hvordan Émile Durkheim er blevet solidt misforstået, når man sammenfatter hans religionsteori i udsagnet 'religion er at et samfund dyrker sig selv'. Durkheims pointe var den modsatte: Religion er at et samfund dyrker et bestemt ideal som det netop ikke er, men som det synes at det burde være. ${ }^{2}$ Aarhus var givetvis ikke fyldt op med Sankt Barbara'er og Hellig Olav'er; men de fleste mennesker i Aarhus anerkendte formentlig at de egentlig skulle være sådan, og at det i princippet var muligt, for andre havde, som tavlen viser, gjort dette: realiseret netop ikke det almene, og heller ikke i streng forstand det over-naturlige, men det mere-end-menneskelige.

Tilsammen repræsenterer disse skikkelser en hel mytologi, der er gået i glemmebogen, bevidst fortrængt og fortiet af protestantiske kræfter og derpå erstattet af ikkekristne mytologier som den antikke eller den nordiske og, vigtigere i dag, af allehånde mediebårne og kortlivede mytologier; hvor Legenda aurea var, kom Ringenes Herre og Game of Thrones. Derved blev middelalderkristendom en religion omtrent lige så fjern og eksotisk som afrikanske eller sydamerikanske indfødtes. Studiet af middelalderkristendom er eksotisk etnografi i tid.

1 If. Sloterdijk 2009, 105 bruges begrebet 'overmenneske' (super homo, jf. superman) første gang af pave Bonifacius 8. i forbindelse med kanoniseringen af den franske konge Ludvig 9. (Saint Louis, Ludvig den hellige).

2 Durkheim 1994 (1912), 600-606; jf. den engelske oversættelse: Durkheim 1995, 422-426. 


\section{Mangfoldighed, analogisme}

Selve tavlens mangfoldighed af figurer er værd at hæfte sig ved. Den franske neostrukturalist Philippe Descola har udmøntet et nyttigt begreb for at forstå hvad pointen kan være i dette mylder. Descola har formuleret en teori om fire fundamentale virkelighedsopfattelser eller 'ontologier' i de menneskelige kulturer igennem historien. ${ }^{3}$ Tre af disse ontologier er hhv. totemisme, hvor væsener, herunder klaner af mennesker, fordeles i grupper med hver sin livsessens i kraft af fælles oprindelse fra bestemte steder i landskabet; animisme hvor dyr og planter er mennesker der normalt er lukket inde i kroppe der sætter bestemte grænser for deres adfærd; naturalisme (vores virkelighedsopfattelse, $\mathrm{i}$ hvert fald officielt, og når vi er på arbejde, fx på universitetet) hvor mennesker fundamentalt ligner alt andet, bortset fra at kun mennesker har bevidsthed og derfor kan danne et utal af forskellige kulturer. Ingen af disse virkelighedsopfattelser passer på altertavlens.

Det gør derimod den fjerde, analogismen, en tænkemåde, en virkelighedsopfattelse, som har domineret højkulturer fra de tidligste bykulturer (og måske fra og med den neolitiske revolution) og frem til engang i 1600-tallet. Begrebet om analogisme er vigtigt religionshistorisk, bl.a. fordi det advarer imod forhastet at kategorisere antikke højkulturers religion sammen med jæger-samler-kulturers religion; når James George Frazer og Rudolf Otto talte om religion, så mente de i første omgang netop arkaisk religion. Og den dominerende virkelighedsforståelse i arkaisk religion var netop analogistisk.

Analogisme vil sige en forståelse af virkeligheden som en ordnet myriade. Virkeligheden består af alt muligt: steder, redskaber, planter, dyr, menneskegrupper, ånder, guder, som tilsammen udgør - eller bør udgøre - en overskuelig og velordnet helhed. If. analogisme hører alting i princippet sammen, og forskellige og konkurrerende analogistiske visioner og teorier kan forstås som enkeltkulturers konkrete bud på hvordan tingene hører sammen. Ofte er der et simpelt princip bag den komplekse mangfoldighed, fx at alting kan ordnes ud fra to, eller tre, eller fire principper (tænk på kinesisk Yin/Yang, indoeuropæisk trefunktionalitet eller asiatiske højreligioners cirkulære og firkantede mandalaer). Altings mangfoldighed er gerne organiseret hierarkisk i en pyramideform, hvor de samme principper gentages fra det øverste til det nederste niveau.

Bag analogistisk tænkning ligger så også angsten for ikke-orden, for kaos, for sammenbrud, for oprør, for at delene ikke kan eller vil ind tage deres rette plads. Og derfor vil analogistisk virkelighedsforståelse fremstå som både konsistent, overskuelig og ikke mindst smuk. Orden og skønhed er samme sag i analogismen. En sådan grundtankegang har været nærliggende og formentlig nødvendig for politiske systemer som i oldtidens bystater og imperier, der skulle kunne håndtere store befolkningsmængder og mange slags kompleksitet med hensyn til fx økonomiske funktioner og etniske identiteter. Og så egner analogistiske ordener sig i særlig grad godt til visuelle repræsentationer, som billeder, skulpturer og bygninger - man kan blot tænke på fx

3 Hovedværket er Descola, Par-delà nature et culture, 2005, engelsk Beyond Nature and Culture, 2013. En første dansk orientering: Lundager Jensen 2016. 
egyptisk, græsk eller aztekisk religion. Processioner, der formentlig er en primær udtryksform for arkaisk religion, ${ }^{4}$ hører med her; også de er konkrete, fylder i rummet og er frem for alt visuelle, selv om de også har været til både at høre og at lugte.

Aarhus-altertavlen er et godt eksempel på en sådan analogistisk mentalitet. Her har opgaven netop været at repræsentere mangfoldighed - der er 39 figurer, dvs. aktører, alt i alt. De står opstillet som til parade, alle står de stille og ret, alle med fronten fremad, alle tilsyneladende villigt accepterende deres status og deres plads i en helhed, der er både forvirrende og dog roligt hvilende, broget og dog, og ikke mindst, skøn. Forgyldningen understreger at dette er en skøn orden. Og den er hierarkisk: Der er tre store skikkelser: Clemens, Anna selvtredje, Johannes Døberen; der er tolv mindre: de tolv apostle, seks på hver side, i to rækker, tre over og tre nede (og i deres indbyrdes hierarkiske orden: de vigtigste, som Peter, Johannes, Jakob og Paulus øverst); der er otte helgeninder der omgiver de tre hovedfigurer; og der er 16 endnu mindre helgener, der omgiver de tolv apostle. Mest slående er den dobbelte triade i hovedfeltet: Den midterste er selv en triade: bedstemoder Anna, datteren Maria og barnebarnet Jesus. ${ }^{5}$

Analogisme vil ikke afbillede virkeligheden, men kun en del af den, den bedre og skønnere del. Altertavlen er udtryk for samme mentalitet som fx Gen 1, den bibelske skabelsesberetning, hvor det er et omkvæd at 'Gud så at det var godt'. 'Godt' er her hebraisk tôb, altså 'godt' i betydningen 'nyttigt', 'brugbart', 'funktionelt' og 'smukt', 'skønt'. Vandene oventil og nedentil, planterne efter deres arter, himmellegemerne, dyrene og menneskene: Det hele er 'godt'. Heri var Gen 1 ikke specielt 'israelitisk', men nærorientalsk. En babylonier eller egypter kunne være uenige i hvad det mest hensigtsmæssige ville være at kalde den guddom der havde indrettet verden: Marduk, Amun, Jahve eller noget andet. Men de ville ikke være uenige om at verden var blevet indrettet hensigtsmæssigt af en omsorgsfuld guddom.

\section{Arkaisk religion}

Aarhus-altertavlen er dermed også et fremragende eksempel på den religionsform, eller den fase i religionens historie, som jeg ovenfor med den amerikanske religionssociolog Robert Bellah har kaldt 'arkaisk religion'. ${ }^{6} \mathrm{Og}$ faktisk kan man få en ret god fornemmelse af et tempel fra oldtiden med dens rigt udsmykkede statuer, dens mange guder, store og små, ved at være i Aarhus Domkirke. En babylonier ville med det samme kunne orientere sig i kirken, kunne forstå hvorfor altertavlen står hvor den gør, både fjernt fra indgangen og centralt i rummet. Tavlen er placeret som et brænd- og forsvindingspunkt, som det sted hvor blikket søger hen, og hvorfra mira-

4 Som jeg foreslår i to artikler i Religionsvidenskabeligt Tidsskrifts temanummer $(66,2017)$ om processioner: Lundager Jensen, 2017a; 2017b.

5 Det er sikkert en tilfældighed at tværsummen af 39 er 12 og tværsummen af 12 er 3 og at dette kunne imitere hovedfeltets dobbelte triadiskhed. Men den der ville synes at et sådan ræsonnement overhovedet kunne være interessant, ville have sans for analogisme.

6 Til Robert Bellahs religionshistoriske skema, jf. Lundager Jensen 2011, og generelt: RvT 60, 2013. 
kuløs kraft udgår. Den signalerer både attraktion og afstand, i den ærke-Rudolf-Ottoske konstellation af mirum, fascinosum og augustum, altså det underfulde og fremmede og ikke mindst opmærksomhedsindfangende, som på én gang siger: kom nærmere! og hold dig på passende afstand!, som Jahve i den brændende tornebusk, hvor den nysgerrige Moses får en skarp ordre om at tage sine sko af, fordi han står på hellig jord, og han har tilstrækkelig arkaisk-religiøs kompetence til at slå blikket ned for ikke at komme til skade (Otto 1920, 91f.). Tavlens guld signalerer også ild, stråler, glorie, alt det der forbindes med arkaiske guddomme, ikke kun den præsteteologiske Jahveherligheds glødende sky, men også de mesopotamiske guder der er omgivet af en lysende melammu, og de iranske guders og kongers $x^{v}$ aranah eller farr. ${ }^{7}$ I de 55 år, tavlen fik til at tjene sin oprindelige funktion, har den været omgivet af røgelsesrøg. Den har ikke kun set godt ud, men også duftet godt, som det passer sig for guddomme og guddommelige ting. En babylonier med normal-kompetence i det religiøse vil have forstået at der her var koncentreret mægtige kræfter, og at respektfuld opførsel, sænket blik, sagte tale var passende. Han (eller hun) ville ikke have genkendt guderne, eller måske havde han identificeret dem forkert; han kunne have spurgt hvorfor Belet-ili, som tydeligvis blev æret her, var fremstillet med en datter, eller hvorfor Sumuqan, vildtets herre, en anerkendt, men normalt noget marginal guddom, havde fået en så fremtrædende plads her i Aarhus? Min hypotetiske babylonier ville have forstået så meget rigtigt at hun eller han nok havde spurgt hvilket af de afbillede væsener der var relevante som beskyttere af fx fremmede besøgende, og hvilke små gaver det kunne være passende at bringe som indledning til et potentielt gavnligt, gensidigt forhold.

Men i så fald ville han eller hun ikke have begået en brøler der var værre end den, Vasco da Gamas folk begik, da de i 1498 som de første europæere gik i land i Calicut på Indiens vestkyst og naivt antog at de stedlige templer var kirker - med godt nok en uventet udgave af Maria i midten (måske en variant af gudinden Kali?) og med ret specielt udseende lokale helgener med lange tænder stikkende en tomme ud af munden og fire eller fem arme. ${ }^{8}$ Vasco da Gamas katolske portugisere antog at indere var kristne, efterkommere af apostlen Thomas' mission. Men denne fejltagelse var kun mulig fordi arkaisk religion er genkendelig på tværs af læresystemer og teologier. Fejltagelsen var altså ikke total, som om katolsk kristendom og sydindisk hinduisme absolut ingen ting havde med hinanden at gøre. Den var snarere en halv fejltagelse:

7 melammu: jf. Black \& Green 1995, 130f.; xvaranah/ farr: “a magic force or power of luminous and fiery nature": Gnoli 1999.

8 Kilden er den officielle beretning om Vasco da Gamas første sejlads til Indien (Gama, et al., 2009, 7577). I denne tekst er der ingen tvivl om at portugiserne identificerer indere de møder først i Malindi (Kenya) og senere i templet i Calicut, som kristne. Men if. udgiveren af den engelske oversættelse, Glen J. Ames, var Vasco da Gama og hans mænd i virkeligheden enten skeptiske med hensyn til om det nu faktisk var kristne, de mødte, eller simpelthen overbeviste om at de ikke var det. Tekstens ordlyd skal da skyldes et hensyn til ønsket hos modtageren af beretningen, den portugisiske konge Manuel 1., om at knytte forbindelser til de kristne der almindeligvis mentes at leve i Indien (ibid., 23). - I øvrigt var der en meget gammel kristen tilstedeværelse i Indien ('Thomas-kristne'), bare ikke dér hvor Vasco da Gama landede (jf. Baum \& Winkler 2003, 107). - Ames' oversættelse er gengivet sidst i denne artikel. 
Hvad der identificeredes, var arkaisk religion eller rettere de postaksiale kompromisreligioner som kristendom og hinduisme hver for sig havde udviklet sig til, og som havde gendannet eller genoptaget en mængde arkaiske træk.

Religionshistorien har traditionelt betragtet de enkelte religioner i analogi med biologiske arter, dvs. som selvreproducerende 'levende systemer'; dermed blev ligheder imellem enkelte religioner enten forstået som 'dybe' fælles træk, nemlig sådanne som gjorde at de overhovedet kunne identificeres som religioner (og som det var religionsfænomenologiens opgave at beskrive), eller som overfladiske og ikke-essentielle randfænomener. Men religioner (og andre kulturelle dannelser) kan givetvis uafhængigt af hinanden antage sammenlignelige former, analogt med det biologiske fænomen 'konvergens' eller 'konvergent evolution'. Hermed menes organismer der med forskelligt ophav antager sammenlignelige former, som $\mathrm{fx}$ hajer og delfiner. Et berømt eksempel er hele den oprindelige australske fauna med dens ræve, mus, bjørne og hoppende planteædere, der alle er pungdyr, Marsurpialia, og som nedstammer fra en og samme art, som har udviklet og uddifferentieret sig og opfyldt nicher der var tilgængelige i deres omverden, og dermed nået frem til former der er stærkt sammenlignelige med placentale arter. ${ }^{9}$ Har en pungræv absolut intet at gøre med en placental ræv, fordi de har forskellig tilblivelseshistorie? Jeg mener jo: De kan godt have alt mulig med hinanden at gøre; de kan være to eksempler på den samme form for tilpasning til sammenlignelige kontekster. Vasco da Gama var ikke i tvivl om at det var religion de stod over for. De var mindre sikre på hvad slags religion det nu var - deres egen eller en anden.

\section{Tavle-had: det aksiale}

Hvis babylonieren forstod tavlen rigtigt, forstod hun eller han dog kun det halve. Det var den samme, arkaiske, halvdel som puristisk indstillede protestanter også forstod, selv om de vurderede dens værdi præcist omvendt: ikke som en mulighed for et varmt venskab, men som diabolsk kætteri og reelt hedenskab. Den protestantiske kritik havde altså ret $\mathrm{i}$ at se polyteisme og billeddyrkelse i denne version af kristendommen; de så arkaisk religion gendannet, og deri havde de ret. Dertil kunne tavlens bagmand og dens forsvarere have svaret at middelalderkristendom ikke blot var regenereret arkaisk religion, men at der var en afgørende forskel. Den arkaiske religions hele formål var at stabilisere og berige, kort sagt velsigne, menneskelivet fra fødsel til grav - og, vel at mærke, ikke mere. Den 180-grader-vending i religionens verden der indtrådte i anden halvdel af det første årtusind f.Kr. og som vi kalder aksetiden, bestod $i$ en fundamentalkritik af etablerede religiøse ordninger. Før kunne mennesker normalt ikke optages i den guddommelige sfære. ${ }^{10}$ Herefter $k a n$ de, forudsat at de lader sig belære og forandrer deres livsførelse fundamentalt.

Men dermed var alt hvad der var vigtigt i den arkaiske religion, også blevet erklæret for nul og niks, for værdiløst og irrelevant - inklusive og ikke mindst, og måske

9 Jf. engelsk Wikipedia: "Convergent evolution"; "pungdyr", Den store danske encyklopædi.

10 Hertil: Lundager Jensen 2012. 
navnlig - guderne, deres templer, deres teologer, deres ofringer, deres statuer og deres fester. I den aksiale vending blev vigtigt til uvigtigt, godt til ondt, smukt til grimt. Som et meget senere, men strengt konsekvent, talerør for dette aksiale princip polemiserede Bernhard af Clairvaux, den asketiske munkeorden Cisterciensernes cheftænker, i 1120'erne voldsomt imod netop skønne ting i kirker. Formuleringen er berømt-berygtet:

“ (...) vi, som nu har forladt Folket, som for Kristi Skyld har lagt bag os alt, hvad der er kostbart og pragtfuldt i Verden, vi, som har fordømt alt det, der straaler skønt, det, der klinger mildt, alt det yndigt duftende, den indsmigrende Visdom, det, der er yndigt at røre, kort sagt fordømt alt det legemligt tillokkende til at være som Skarn for os, for at vi kan vinde os Kristus: jeg spørger: hvis Fromhed søger vi at opildne ved disse ting? Hvilken Frugt søger vi af disse ting? Mon den beundring, Taaberne kender, eller den Fryd, de enfoldige har derved?"11.

If. Bernhard vil Aarhus-tavlen ikke være andet end 'som skarn', latin ut stercora, altså som ko-lort. Det aksiale er at kunne lugte ko-lort, hvor almindelige mennesker - altså tåberne, de enfoldige - i deres naivitet kun sanser velduftende røgelse.

If. Durkheim kom al kultur af religion. If. Weber kom ikke mindst religionskritikken af religion (nemlig den aksiale kritik). Den aksiale kritik imod den arkaiske religion blev gentaget inden for kristendommen selv. Den radikale konsekvens af et standpunkt som Bernhards ville være at munkene var trådt ud af kirken, op af den stinkende mødding, og etableret sig som den sande, rene og velduftende kirke. Det skete ikke; cistercienserne ville netop vise radikale kritikere som katharerne at det var muligt at være både inde i og uden for kirken på samme tid. Bernhard ville have at cisterciensernes klostre skulle have hvide vægge, uden udsmykning, så munkene kunne koncentrere sig om bøn, sang og læsning og ikke distraheres af tåbelige billeder (Duby 1979, 88.125-127). Kirkeinstitutionen, den sekulære kirke, valgte på sin side klogelig at være relevant religion også for tåber og enfoldige og disses små bekymringer for deres liv før døden. Det var derfor nærorientalsk, arkaisk religion allerede i oldkirken blev gendannet, nu som kristendom, som en religion også for dette liv, at den også blev en ny udgave af en religion, der som de gamle religioner stabiliserede, hjalp, helbredte, trøstede, og fodrede fantasien med skønhed og med en myldrende mytologi.

11 Bernhard af Clairvaux, Apologia ad Guillelmum; dansk oversættelse: Bernhard af Clairvaux 1926, 263. - Latinsk tekst: “Nos vero qui jam de populo exivimus; qui mundi quaeque pretiosa ac speciosa pro Christo reliquimus; qui omnia pulchre lucentia, canore mulcentia, suave olentia, dulce sapientia, tactu placentia, cuncta denique oblectamenta corporea arbitrati sumus ut stercora, ut Christum lucrifaciamus: quorum, quaeso, in his devotionem excitare intendimus? Quem, inquam, ex his fructum requirimus? stultorum admirationem, an simplicium oblationem?" (http://www.binetti.ru/bernardus/14.shtml; set 2018-04-11). 


\section{Kompromisreligion}

Mellem den aksiale og den arkaiske tendens bestod hele tiden et usikkert og vaklende kompromis; men så længe den vaklede, stod den. Kirkeledelsen måtte konstant overvåge at hverken den ene eller den anden tendens gik for vidt. Denne fastholdelse af de to poler i et gensidigt spændingsforhold sker i altertavlen, med Sankt Clemens i sit biskoppeligt-pavelige skrud, dvs. institution, tradition, fasthed i centrum, i midten af Aarhus, og i Rom, altså i midten af verden - over for Sankt Hans, Johannes Døberen, barbenet i pjalter, en røst i ørkenen, dvs. uden for det beboede land, borte fra byen (Jerusalem, Aarhus), hinsides agerbruget, derude hvor eneboere spiser græshopper og vilde biers honning, altså mad der på én gang er den rene elendighed $o g$ vidunderlig overflod (Lévi-Strauss 1966, 11 et passim), ekstremt lidt og mere end tilstrækkeligt.

Dette er som sagt ikke en fuldstændig analyse af underforståede temaer og programmer i altertavlen. Clemens og Johannes optræder naturligvis også i deres egenskaber af patroner, beskyttere: Clemens er patron for domkirken og for Aarhus, og Johannes er sandsynligvis patron for biskop Jens selv, der jo bar hans navn: Jens er Johannes på lokalsprog (også selv om altertavlens portræt af biskop Jens viser ham beskyttet af evangelisten Johannes). Der er formentlig meget mere. Fx er det påfal-

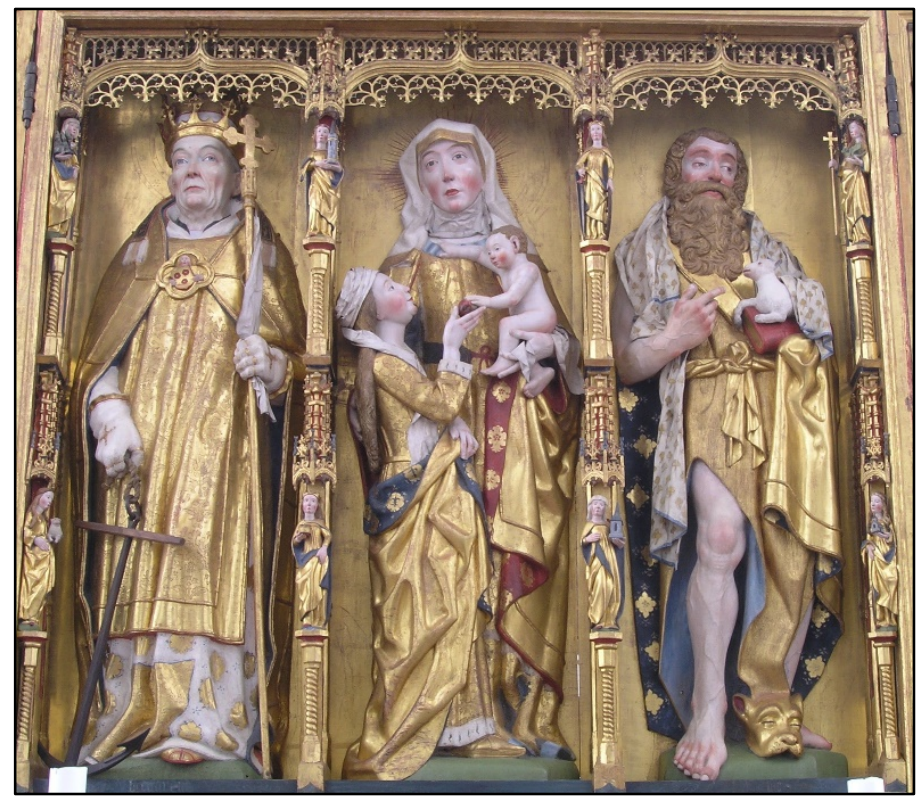

Foto: Jens Bruun@.

dende hvordan tavlen også administrerer forholdet imellem det mandlige og det kvindelige. Ingen tvivl om at de hellige mænd numerisk overgår de hellige kvinder (hhv. 30 og 10, hvis Anna og Maria hver tæller for én). Men centrum i det hele, den altdominerende figur, er hverken biskoppen eller Johannes, men mutter Anna, velbjerget borgerfrue, sikkert en af biskoppens og kirkens mest loyale støtter. Anna repræsenterer måske lægfolket, der her holder de to potentielle kamphaner fra at gå i 
håndgribelig infight. Jeg vil her kun nævne muligheden af at Anna også kunne tænkes at repræsentere noget andet end lægfolket slet og ret: Måske er hun også det religiøst aktive lægfolk, den religiøse retning i 1300-1400-tallet der omtales som devotio moderna, en forløber for pietismen, som det var vigtigt at holde øje med. Man kunne aldrig vide hvad overdreven amatørteologi kunne føre til. I så fald står Anna også flankeret af to principper som man dog ved hvad er: biskop- og domkirkereligion på den ene side, og klosterreligion på den anden side.

Formentlig dominerer biskoppens og domkirkens religion trods alt her munkens og klostrets religion: Tavlen vælger skønheden, det visuelle; den har forgyldt alt, inklusive den guldløse Johannes, og den er fremstillet til en domkirke, ikke et kloster. Til Bernhards dualisme med dens modstilling imellem tumper og intelligente vil den sige at der er plads til dem begge, og at en religion der gerne vil vare ved, gør klogt i at være religion også for tumper. Men derved får tavlen også noget tragisk over sig, som jeg vil vende tilbage til.

Selvfølgelig kan man også se altertavlen som udtryk for magt, både i Marxsk og i Nietzscheansk-Foucaultsk forstand. Altertavlen er et resultat af en tilegnelse af en merværdi der er frembragt $\mathrm{i}$ den materielle produktion og en akkumulation - og i dén forstand forbinder den antikkens euergetisme, romerske mæceners donationer til almenvellet, både fester og offentlige byggerier, med modernitetens industriherrers omveksling af kapital til kunst og viden (Carnegie, Rockefeller, Vanderbilt, Carl Jacobsen, Mærsk McKinney Møller). Altertavlen vil også legitimere et magtforhold imellem biskop og alle andre - et magtforhold som heller ikke dengang var hævet over kritik. Den siger: 'Ja, jeg er rig; men se hvad jeg bruger min rigdom til'. Og altertavlen er åbenlyst et udslag af biskop Jens vilje til magt, vilje til at bestemme bl.a. hvad der er sand religion, herunder hvilke helgener der skal æres hvor meget i Aarhus åbenlyst for han anbragte sit slægtsvåben, de tre roser, på brystet af statuen af Sankt Clemens og antydede måske derved at forskellen imellem den gamle pave og ham selv var minimal? Problemet med dette syn på altertavlen er ikke at det er forkert, men at det er trivielt. Dels indeholder det ingen ny erkendelse, dels vil det i sin mest militante udgave - der ikke kun ligner det radikalprotestantiske billedstormeri, som i det vestlige Europa i 1500-tallet knuste og brændt altertavler, men formentlig også er historisk forbundet med det - indebære et konsekvensmageri, der i sidste ende vil delegitimere al form for kunst og skønhed.

Mere relevant er det at se de religionshistoriske processer bag tavlen, ikke kun op til og samtidig med dens tilblivelse, som jeg har gjort det her i min analyse af spændingen imellem det sekulærgejstlige og det regulærgejstlige (og måske lægfolksfromheden), altså imellem den rige biskop, den fattige asket og den fromme borgerfamilie - men også efter. Umiddelbart udstråler tavlen soliditet, sikkerhed, overskud, rigdom. Pave Clemens' årvågne, men bekymrede blik udtrykker vilje til at beskytte sin kirke og sin by og at holde kirken og dens samfund sammen, at holde styr på de mange hellige, store som små, sikre at de står på deres pladser og holder sig i deres nicher. Formentlig hviler hans blik også vagtsomt og beskyttende på Aarhus by og bispedømme. 


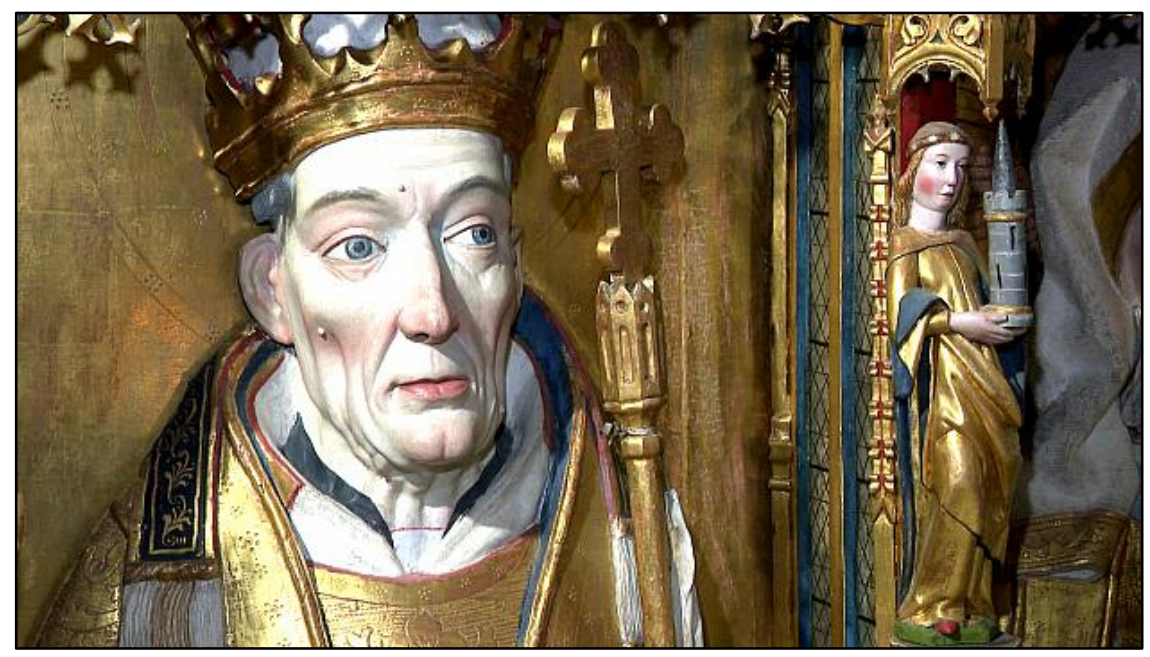

Pave Clemens, detalje fra altertavlens hovedfelt; fra https://www.tv2ostjylland.dk/artikel/11-aars-stoev-skal-fjernes-det-er-et-aerefuldt-job

$V i$ ved at det ikke var nok. 55 år senere var det meste af denne orden kollapset. Reformationen fejede helgenerne $\mathrm{ud},{ }^{12} \mathrm{dæmoniserede} \mathrm{paven,} \mathrm{havde} \mathrm{ikke} \mathrm{brug} \mathrm{for} \mathrm{Clemens}$ og Rom mere, gjorde Anna irrelevant, forkastede de otte beskyttende jomfruer. I de lutherske lande sikrede staten så ganske vist at der ikke skete de ødelæggelser af religiøse billeder som fandt sted andre steder i Nord- og Vesteuropa, i Schweiz, Nederlandene, Frankrig og England. Altertavlen blev dermed også gjort til et monument over en kun moderat foragt for forgængere og forløbere - alt det som kirkelige talsmænd ellers gjorde sig store anstrengelser for at lære andre ikke at forstå og ikke at sympatisere med. Altertavlen blev på sin vis luthersk-protestantisk, ikke i kraft af dens papistisk-katolske indhold, som var umuligt at evangelisere, men i sin blotte overlevelse, i det rene faktum at den fik lov til at blive stående, som et religiøst reservat, en beskyttet bolig, en underlig ting i et raritetskabinet. Der har vel været nogle i Aarhus der syntes at den trods alt var ret flot.

Med den viden, som vi har, er det relevant også at se altertavlen som et fortvivlet forsøg på at stabilisere en orden, der gik sin undergang i møde. Formentlig forestillede biskop Jens sig ikke en reformation, selv om han havde god grund til at frygte et sammenbrud. Der var talrige forsøg i middelalderen på at rive kirke, kloster og lægfolk fra hinanden. Det postaksiale kompromis imellem det arkaiske og det aksiale, imellem religion for livet indtil graven og for livet efter graven, imellem guddommelige hjælpere ovenfra og over-mennesker nedenfra, mellem mirakler og belæring, var

12 Selv om udfejningen angik altre, mere end kalkmalerier. Det hvide kirkeindre skyldes ikke den lutherske reformation, men 1700-tallets rationalisme og pietisme (Bøgh, 2015). Jf. Erik Pontoppidans skrift fra 1736, Everriculum fermenti veteris: Fejekost: til at udfeje den gamle surdejg eller de i de danske lande tiloversblevne og her for dagen bragte levninger af saavel hedenskab som papisme. 
som sagt konstant vaklende. Til sidst styrtede kompromiset sammen. Lysene slukkedes på de 40 altre, der skal have været i gang i Aarhus Domkirke (Bjørn \& Gotfredsen 1996, 130), og tilbage stod et eneste alter, det største og det mest kostbare. Det postaksiale kompromis fik lov at blive stående, formentlig som en gammel og fin ting ('kunst' vil nok være en anakronisme), som erindring, eller snarere som en forvirrende antydning af en viden der har været, og som forekommer irrelevant i dag. Al religion, al kultur, eksisterer kun i kraft af stadig selvopretholdelse, revitalisering, genbekræftelse, som Durkheim har vist os. Biskop Jens gjorde hvad han kunne.

\section{LITTERATUR}

Baum, Wilhelm \& Dietmar W. Winkler

2003 The Church of the East: A Concise History, Routledge.

Bernhard af Clairvaux.

1926 Bernhard af Clairvaux. Hans Liv fortalt af Samtidige og et Udvalg af hans Værker og Breve, oversat af C.P.O. Christiansen. Selskabet for historiske Kildeskrifters Oversættelse, Schønberg.

Bjørn, Hans \& Lise Gotfredsen

1996 Århus domkirke Skt. Clemens, Århus Domsogns Menigshedsråd, 1996.

Black, Jeremy \& Anthony Green

1995 Gods, Demons and Symbols of Ancient Mesopotamia. An Illustrated Dictionary, University of Texas Press.

Bøgh, Anders

2015 "Myte: Blev de danske kirkers kalkmalerier overkalket efter reformationen i 1536?", https://danmarkshistorien.dk/

Descola, Philippe

2005 Par-delà nature et culture, Gallimard; oversat af Janet Lloyd: Beyond Nature and Culture, Chicago University Press 2013.

Duby, Georges

1979 Saint Bernard. L'art cistercien, Flammarion.

Durkheim, Émile

1994 Formes élementaires de la vie religieuse, Quadrige / Presses universitaires de France (oprindeligt: 1912).

1995 The Elementary Forms of Religious Life, oversat af Karen E. Fields, The Free Press.

Gnoli, Gherardo

1999 “Farr(ah)", Encyclopædia Iranica. On-line: http://www.iranicaonline.org/articles/farrah

Kaspersen, Søren

1999 “Højalter, liturgi og andagt: betragtninger over Bernt Notkes alterskab i Århus”, Hikuin 26, 101134.

Lévi-Strauss, Claude

1966 Du miel aux cendres, Plon.

Lundager Jensen, Hans J.

2003 "Roy Rappaport: Ritual and Religion in the Making of Humanity", Religionsvidenskabeligt Tidsskrift 43, s. 71-77. https://doi.org/10.7146/rt.v0i43.1901

2011 "Religionshistorie og aksetid", Religionsvidenskabeligt Tidsskrift 56, 5-22.

2012 "Shiduris belæring", in: Søren Holst \& Christina Petterson, eds., Den store fortælling. Festskrift til Geert Hallbäck, Anis, 231-246.

2016 “Ontologier i Det Gamle Testamente: Analogisme og animisme (Gen 1 og 2-3)”, Collegium Biblicums Årsskrift 20, 1-19. 
2017a "Processioner: Indledning", Religionsvidenskabeligt Tidsskrift 66, 3-13.

https://doi.org/10.7146/rt.v0i66.26445

2017b "Om dejlige dage: Hiero- og teofore processioner i arkaisk religion og i Det Gamle Testamente", Religionsvidenskabeligt Tidsskrift 66, 78-104. https://doi.org/10.7146/rt.v0i66.26448

Moltke, Erik

1970 Bernt Notkes altertavle i Århus domkirke og Tallintavlen, Gad.

Otto, Rudolf

1920 Das Heilige: Über das Irrationale in der Idee des Göttlichen und sein Verhältnis zum Rationalen, 4. oplag, Breslau (oprindeligt 1917).

Plathe, Sissel F. \& Jens Bruun

2010 Danmarks Middelalderlige Altertavler, Bd. 1-2, Syddansk Universitetsforlag.

Pontoppidan, Erik

1923 Fejekost: til at udfeje den gamle surdejg eller de $i$ de danske lande tiloversblevne og her for dagen bragte levninger af saavel hedenskab som papisme, oversat og forsynet med indledning af Jørgen Olrik, Schønberg.

Rappaport, Roy A

1999 Ritual and Religion in the Making of Humanity, Cambridge University Press.

Sloterdijk, Peter

2009 Du musst dein Leben ändern. Über anthropotechnik, Suhrkamp. https://doi.org/10.1017/CBO9780511814686

Vasco da Gama

2009 Em nome de Deus: The Journal of the First Voyage of Vasco da Gama to India, 1497-1499, translated and edited by Glenn J. Ames, Brill.

Tekster på internettet:

Bøgh, Anders

2015 "Myte: Blev de danske kirkers kalkmalerier overkalket efter reformationen i 1536?", danmarkshistorien.dk (set 2018-04-12)

Forham Historical Sourcebook https://sourcebooks.fordham.edu/halsall/mod/1497degama.asp (set 2018-04-11)

Hans J. Lundager Jensen, prof., dr. theol Afdeling for Religionsvidenskab, Aarhus Universitet hj@cas.au.dk

Tillæg:

Den officielle beretning om Vasco da Gama og hans mænds første møde med et hinduistisk tempel; fra: https://sourcebooks.fordham.edu/halsall/mod/1497degama.asp

When we disembarked, the captain-major once more entered his palanquin. The road was crowded with a countless multitude anxious to see us. Even the women came out of their houses with children in their arms and followed us. When we arrived (at Calicut) they took us to a large church, and this is what we saw: The body of the church is as large as a monastery, all built of hewn stone and covered with tiles. At the main entrance rises a pillar of bronze as high as a mast, on the top of which was perched a 
bird, apparently a cock. In addition to this, there was another pillar as high as a man, and very stout. In the center of the body of the church rose a chapel, all built of hewn stone, with a bronze door sufficiently wide for a man to pass, and stone steps leading up to it. Within this sanctuary stood a small image which they said represented Our Lady. Along the walls, by the main entrance, hung seven small bells. In this church the captain-major said his prayers, and we with him.

We did not go within the chapel, for it is the custom that only certain servants of the church, called quafees, should enter. These quafees wore some threads passing over the left shoulder and under the right arm, in the same manner as our deacons wear the stole. They threw holy water over us, and gave us some white earth, which the Christians of this country are in the habit of putting on their foreheads, breasts, around the neck, and on the forearms. They threw holy water upon the captain-major and gave him some of the earth, which he gave in charge of someone, giving them to understand that he would put it on later. Many other saints were painted on the walls of the church, wearing crowns. They were painted variously, with teeth protruding an inch from the mouth, and four or five arms. Below this church there was a large masonry tank, similar to many others which we had seen along the road. 